\title{
URINARY EXCRETION OF 17-KETOSTEROIDS IN CHILDREN
}

\author{
BY \\ MARGARET PROUT and A. H. SNAITH \\ From The Hospital for Sick Children, Great Ormond Street, London
}

(RECEIVED FOR PUBLICATION JANUARY 29, 1958)

Determination of the urinary excretion of 17-ketosteroids (17-oxosteroids) is the most important laboratory test in the investigation of endocrine disorders involving the adrenal cortex and gonads in children. The normal range of excretion varies with the method employed, since non-steroidal pigment may to a greater or lesser degree be measured as 17-ketosteroid. It is important therefore to know the normal range for the method used. This applies particularly to children, in whom excretion rises with age. In this paper normal values for the two most commonly used methods are given as well as figures for the commoner pathological conditions in which 17-ketosteroid excretion is raised. The evaluation of 17 -ketosteroid excretion in pathological disorders is discussed.

\section{Methods}

Extraction. Twenty-four-hour urines from 73 normal children were extracted as follows. After the volume of the specimen had been measured, $100 \mathrm{ml}$. were brought to the boil on a hot-plate, and $15.0 \mathrm{ml}$. of concentrated hydrochloric acid poured down the reflux condenser. Boiling was continued for exactly 10 minutes. The urine was then cooled under the tap and extracted with $2 \times 75 \mathrm{ml}$. and $1 \times 50 \mathrm{ml}$. of ether. The ether extract was washed with $2 \times 15 \mathrm{ml}$. of $10 \%$ sodium hydroxide, $1 \times 10$ $\mathrm{ml}$. of a saturated solution of sodium hydrosulphite and then with water until the aqueous layer was neutral to litmus. After draining off all the water the ether was dried by adding a little anhydrous sodium sulphate and swirling. The ether was filtered (glass wool) and evaporated on a water bath using an air leak. Extracts were desiccated overnight. Each extract was then dissolved in $2.0 \mathrm{ml}$. of absolute alcohol and aliquots of $0.20 \mathrm{ml}$. removed for estimation.

Methods of Estimation. Method 1. Four tubes were set up. The first contained $0.2 \mathrm{ml}$. of extract, $0.2 \mathrm{ml}$. of $2 \cdot 0 \% \mathrm{~m}$-dinitrobenzene and $0 \cdot 1 \mathrm{ml}$. of $5 \cdot 0 \mathrm{~N}$. aqueous potassium hydroxide; in the second tube $0.2 \mathrm{ml}$. of absolute alcohol was substituted for m-dinitrobenzene (=control); in the third tube $\mathbf{0 . 2} \mathrm{ml}$. of absolute alcohol was substituted for the extract (=reagent blank); in the fourth tube $0.2 \mathrm{ml}$. of absolute alcohol containing
$50 \mu \mathrm{g}$. dehydroepiandrosterone was substituted for the extract. The tubes were incubated in a water bath at $25 \cdot 0 \pm 0 \cdot 2^{\circ} \mathrm{C}$. for 60 minutes in the dark and then to each tube was added $10.0 \mathrm{ml}$. of $70 \%$ ethanol. Readings were made in the Spekker (Hilger absorptiometer) using filter 604 and $70 \%$ alcohol as blank. Control and reagent blanks were subtracted from the reading. The amount of 17-ketosteroid present in the test was calculated by comparison with the standard reading (fourth tube) and the total for the 24-hour urine derived from this. This method of estimation has been in routine use in this hospital for many years and is similar to that of Holtorff and Koch (1940).

Method 2. In this method of estimation, which employs alcoholic in place of aqueous potassium hydroxide, the correction factor of Talbot, Berman and MacLachlan (1942) recommended by the Medical Research Council (1951) was used. To the first tube was added $0.2 \mathrm{ml}$. of extract, $0.2 \mathrm{ml}$. of $2.0 \% \mathrm{~m}$-dinitrobenzene, and $0.2 \mathrm{ml}$. of $2 \cdot 50 \%$ potassium hydroxide in absolute alcohol. Appropriate reagent blank and standard tubes were set up. After dilution with $10.0 \mathrm{ml}$. of absolute alcohol, readings of the test in the Spekker, using the green (604) and violet (601) filters were obtained and after subtracttion of the blanks the corrected reading was obtained from the formula of Talbot et al. (1942); corrected reading= $\frac{\mathrm{Eg}=0.6 \mathrm{Ev}}{0.72}$

Various methods of correction for non-steroidal pigments were investigated as follows:

Method 3. As in method 2, except that the Hilger Uvispek was substituted for the Spekker, readings being taken at $515 \mathrm{~m} \mu$. (in place of the green filter) and $425 \mathrm{~m} \mu$. (in place of the violet filter), the above formula being applied.

Method 4. As for method 3, but readings were made at $425 \mathrm{~m} \mu$., $515 \mathrm{~m} \mu$. and $605 \mathrm{~m} \mu$., and the corrected test obtained from the formula of Allen (1950), in which the corrected reading $=\mathrm{E} 515-\frac{\mathrm{E} 605+\mathrm{E} 425}{2}$

Method 5. As in method 1 but the Hilger Uvispek was used and the corrected reading obtained as in method 4 .

Results

The results for the five methods of estimation are given in Table 1. Only 57 of the 73 urines were estimated by 
methods 3, 4 and 5. For convenience the means of four age groups with standard deviations are given for methods 1 and 2 in Table 2.

TABLE 1

17-KETOSTEROID EXCRETION IN NORMAL CHILDREN

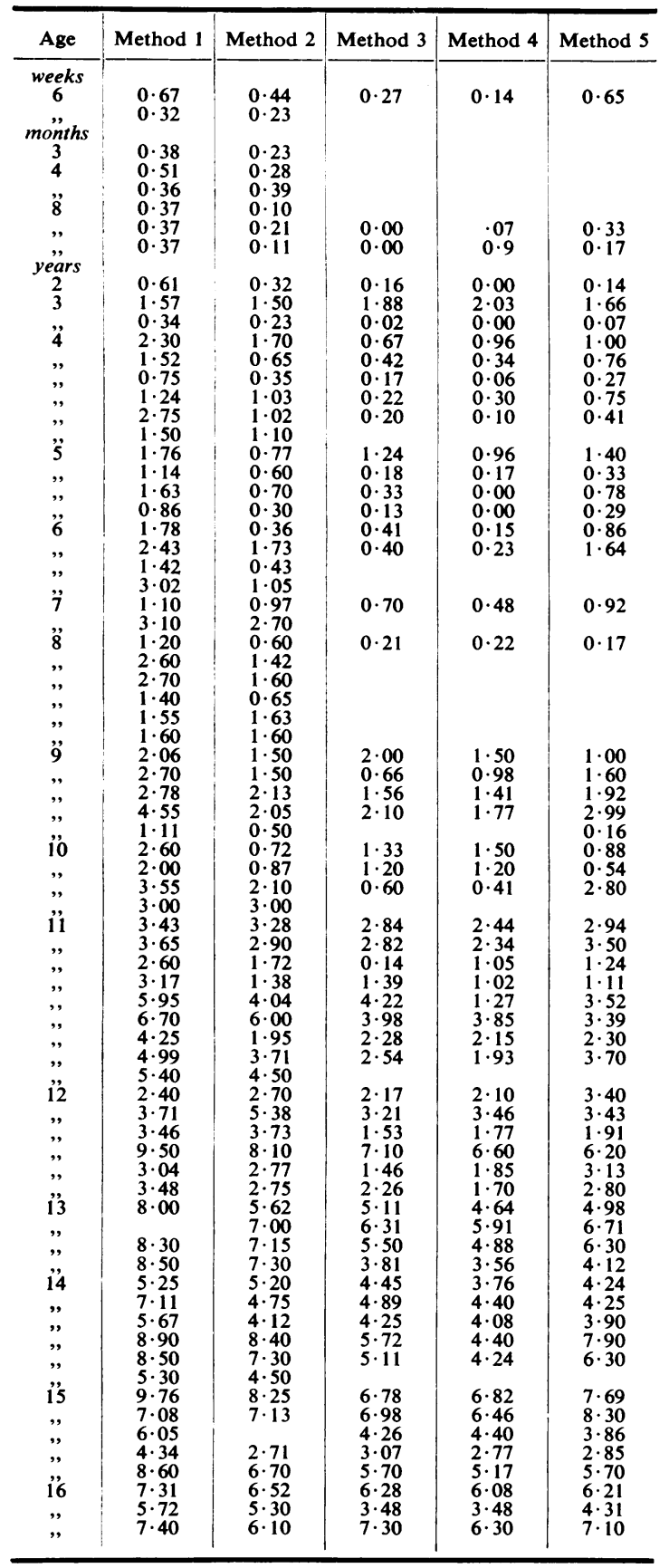

TABLE 2

MEAN EXCRETION OF 17-KETOSTEROIDS IN CHILDREN OF DIFFERENT AGE GROUPS

\begin{tabular}{c|c|c}
\hline $\begin{array}{c}\text { Age Groups } \\
\text { (years) }\end{array}$ & $\begin{array}{c}\text { Method 1 } \\
\text { (mg./24 hr.) }\end{array}$ & $\begin{array}{c}\text { Method 2 } \\
\text { (mg./24 hr.) }\end{array}$ \\
\hline $0-1$ & $0 \cdot 47 \pm \cdot 16$ & $0 \cdot 25 \pm \cdot 12$ \\
$1-5$ & $1 \cdot 38 \pm .66$ & $0 \cdot 78 \pm .46$ \\
$6-10$ & $2 \cdot 30 \pm .85$ & $1 \cdot 38 \pm .74$ \\
$11-17$ & $6 \cdot 03 \pm 2 \cdot 14$ & $4 \cdot 96 \pm 2 \cdot 06$ \\
\hline & \\
&
\end{tabular}

17-ketosteroid Excretion in Normal Children. The urinary excretion of 17-ketosteroids in children has been reported by many authors and results have varied considerably. A comparison of results by various methods has been made by Poli and Fantuzzi (1945). The results quoted for different laboratories by Dorfman (1952), all by the Holtorff and Koch (1940) method, are high compared with the results reported here. The results obtained by method 2 are in closer agreement with results reported by others who have used a similar method. Miller and Mason (1945) found averages of approximately $5.7 \mathrm{mg}$. in boys and $5 \cdot 2 \mathrm{mg}$. in girls for the age group 12-17 years, while Talbot, Butler, Berman, Rodriguez and MacLachlan (1943) found an average excretion of $0.4 \mathrm{mg}$. at 5 years, and of $1.9 \mathrm{mg}$. at 10 years. Hain (1947) obtained figures for the 5-10 age group which are somewhat higher, about $3.5 \mathrm{mg}$. in boys and $2.0 \mathrm{mg}$. in girls. Bongiovanni (1951) employed aqueous potassium hydroxide, but corrected for the interfering pigments by extracting the developed colour with chloroform, and by this method obtained figures which were comparable with those of Talbot et al. (1943).

The three chief causes of variation are probably: (a) Differences in the method employed for estimating the 17-ketosteroids after extraction from the urine. (b) Differences in the method of extraction. (c) Race differences (Barnicot and Wolffson, 1952).

Only the first has been considered here. It is evident from Table 1 that the highest values are obtained by method 1 , lower values with method 2 , and values which are lower still with methods 5,3 and 4 in that order. These differences are greater in the lower two age groups, illustrating that what is measured by methods 1 and 2 in these groups is to a greater extent non-steroidal pigment. The much lower results obtained by method 5 , compared with method 1 , is indicative of the degree to which the results are erroneously high in the latter method. Method 5 is not a valid procedure, however, because when aqueous potassium hydroxide is employed the Zimmerman reaction does not obey Beer's law. Although methods 3 and 4 give lower results than 
method 2, the latter is a satisfactory routine procedure and superior to method 1 . The normal range will vary according to the method of extraction employed, but differences from the results obtained here should not be great provided special purification methods, e.g. Girard's reagent, or chromatography, are not used.

Raised 17-ketosteroid Excretion in Children. The determination of the 17 -ketosteroid excretion is of clinical importance in childhood in congenital adrenal hyperplasia, tumours of the adrenal cortex, and precocious puberty. It is not possible to distinguish one condition from the other by the level of excretion. In children of 5 or 6 years with hyperplasia excretion may be as little as $10 \mathrm{mg}$./24 hours (Table 3, Cases 9 and 12), or approaching $100 \mathrm{mg}$./ 24 hours (Table 3, Cases 13 and 32), levels which are more typical, possibly, of adenoma or carcinoma of the adrenal cortex. In all of the cases of adrenal hyperplasia (Table 3), the first 17-ketosteroid determination was abnormally high, i.e. more than the mean $+2 \times$ standard deviation. In Case 5 , the 17-ketosteroids, determined during the first week or two of life at another hospital, were less than $1.0 \mathrm{mg}$. $/ 24$ hours and this was passed as normal. It is possible therefore that very low figures may be observed in early infancy and if the diagnosis is thought probable a second specimen should be examined either immediately or in three months' time.

In congenital adrenal hyperplasia the presence of a raised pregnanetriol excretion is diagnostic, but borderline figures may occur here also in the young infant, as in Case 15, in which pregnanetriol excretion was only $0.2 \mathrm{mg}$. $/ 24$ hours rising after ACTH to $0.45 \mathrm{mg} . / 24$ hours (Case 1, Table 4). (The mean excretion of pregnanetriol in 12 normal children of all ages was $0.04 \mathrm{mg}$. $/ 24$ hours with a range of $0-0 \cdot 18 \mathrm{mg} . / 24$ hours.) The raised 17 -ketosteroid excretion was therefore of particular significance in this case, especially in view of the fact that the urogenital sinus which was present could possibly have been explained by hormone treatment which the mother had received during the early part of her pregnancy.

It sometimes happens that a child, usually 2 or 3 weeks of age, is admitted to hospital in collapse due to adrenal insufficiency associated with adrenal hyperplasia. Steroid therapy may be commenced immediately and cannot subsequently be withdrawn because of the danger of precipitating a second collapse. Urinary steroid determinations may not, therefore, be carried out, or if they are interpretation may be difficult because of the suppression of the
TABLE 3

17-KETOSTEROID EXCRETION IN CONGENITAL ADRENAL HYPERPLASIA, IN BOYS WITH PRECOCIOUS PUBERTY AND IN ADRENOCORTICAL TUMOURS (ESTIMATED BY METHOD 1)

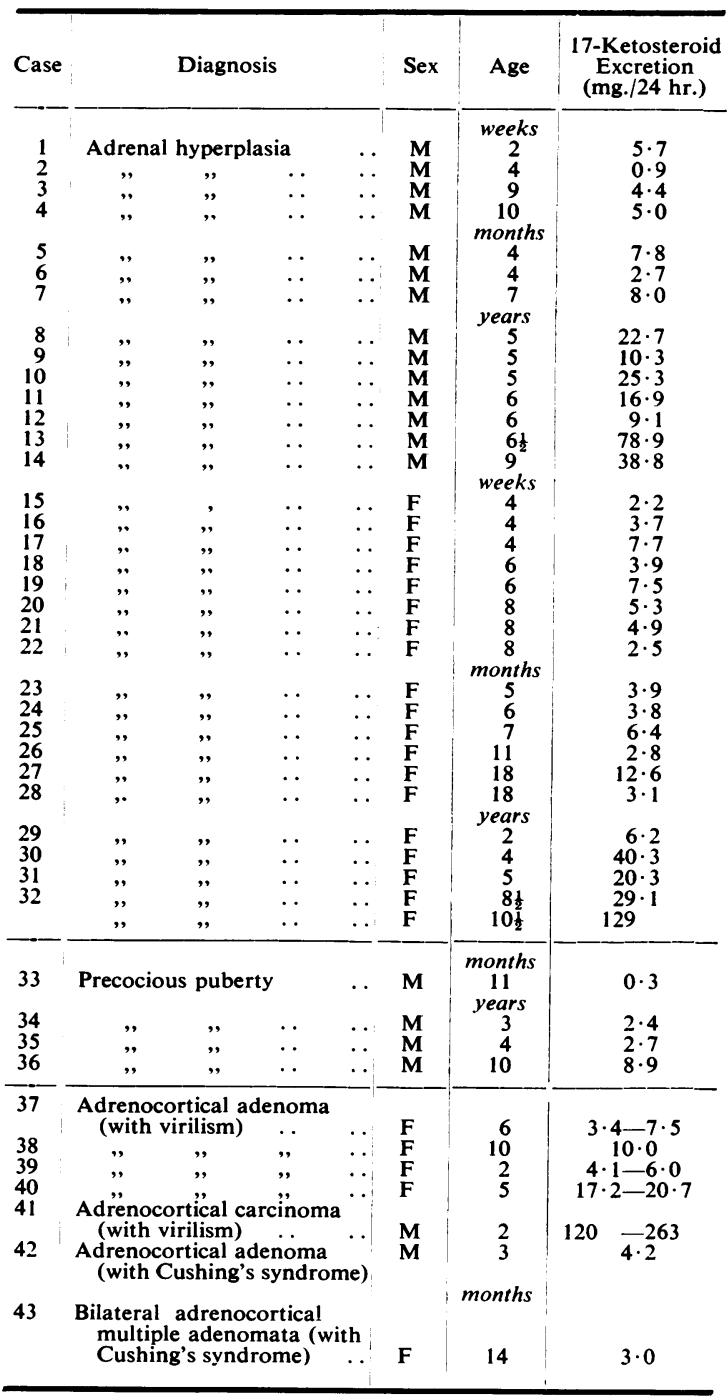

cortex due to the administered hormones. In this event it is important to re-admit the child in order to establish the diagnosis. If suppressive treatment is withdrawn the 17-ketosteroids will be found to rise to a diagnostic level; if suppressive steroids cannot be withdrawn it may be found that the urinary pregnanetriol excretion, though partly suppressed, is still abnormally high. It is important to establish the diagnosis in a case which presents in this way because cases occur in which the plasma electrolytes are 
TABLE 4

17-KETOSTEROIDS AND PREGNANETRIOL EXCRETION BEFORE AND AFTER ACTH $10 \mathrm{mg}$. 24 HOURS (CASE 1) AND $40 \mathrm{mg} . / 24$ HOURS (CASES 2, 3 AND 4) FOR THREE DAYS

\begin{tabular}{|c|c|c|c|c|}
\hline \multirow[b]{3}{*}{$\begin{array}{l}\text { 17-ketosteroid } \\
\text { before ACTH } \\
\text { after ACTH }\end{array}$} & Case 1 & Case 2 & Case 3 & Case 4 \\
\hline & \multicolumn{4}{|c|}{ (values in mg./24 hr.) } \\
\hline & $\begin{array}{l}2 \cdot 2 \\
3 \cdot 5\end{array}$ & $\begin{array}{r}7 \cdot 3 \\
13 \cdot 8\end{array}$ & $\begin{array}{r}7 \cdot 7 \\
23 \cdot 4\end{array}$ & $\begin{array}{l}30 \cdot 1 \\
39 \cdot 7\end{array}$ \\
\hline $\begin{array}{l}\text { Pregnanetriol } \\
\text { before ACTH } \\
\text { after ACTH }\end{array}$ & $\begin{array}{l}0.2 \\
0.4\end{array}$ & $\begin{array}{l}20 \cdot 5 \\
15 \cdot 0\end{array}$ & $\begin{array}{l}14 \cdot 0 \\
37 \cdot 0\end{array}$ & $\begin{array}{l}20 \cdot 0 \\
36 \cdot 8\end{array}$ \\
\hline
\end{tabular}

typical of adrenal insufficiency, though there is no confirmatory evidence of this. In two such cases, both boys, aged 5 and 9 weeks of age, the 17-ketosteroids were raised and subsequently fell. The figures in mg./24 hours were $1 \cdot 10 ; 0.85 ; 0.81 ; 0.56$; and $1 \cdot 80 ; 1 \cdot 13$ and 1.00 respectively. It is possible that the 17-ketosteroids were raised as a result of the illness. Such cases might be diagnosed incorrectly as having congenital adrenal hyperplasia. While a provisional diagnosis of hyperplasia can be made on the basis of abnormal plasma electrolyte levels in male infants, and on the presence of a urogenital sinus with or without associated abnormal plasma electrolyte levels in girls, a definitive diagnosis can only be made by the investigation of urinary steroid excretion.

In boys with precocious puberty the 17-ketosteroids may be raised to levels characteristic of the physiological age but are unlikely to exceed $10 \mathrm{mg}$./ 24 hours. If 17-ketosteroid excretion is less than $10 \mathrm{mg}$. a day in a boy, the distinction between the virilizing tumour and precocious puberty must be made on clinical grounds. A raised gonadotrophin excretion would support a diagnosis of precocity, and in adrenocortical tumours the testes are likely to be normal in size for the chronological age. A diagnosis cannot be established on those grounds, however, and special investigations will be required to exclude a tumour.

ACTH tests are of little importance in the diagnosis of congenital adrenal hyperplasia. After administration of ACTH, $20 \mathrm{mg}$. b.d. for three days, pregnanetriol excretion in a normal child was $0.4 \mathrm{mg}$. $/ 24$ hours on the third day. In adrenal hyperplasia pregnanetriol and 17-ketosteroid excretion usually rise after ACTH administration, but this is not invariable (Table 4).

\section{Summary}

The excretion of 17-ketosteroids by normal children and by children with congenital adrenal hyperplasia, adrenocortical tumours, and with precocious puberty has been determined. The clinical evaluation of 17-ketosteroid excretion is discussed.

We wish to thank the physicians and surgeons of The Hospital for Sick Children, Great Ormond Street, for permission to study their cases, and the Research Com. mittee for their support.

\section{REFERENCES}

Allen, W. M. (1950). J. clin. Endocr., 10, 71.

Barnicot, M. A. and Wolffson, D. (1952). Lancet, 1, 893.

Bongiovanni, A. M. (1951). J. Pediat., 39, 606.

Dorfman. R. I. (1952). Ciba Foundation Colloquia on EndocrinDorm, Vol 2, p. 160

Hain, A. M. (1947). Arch. Dis. Childh., 22, 152.

Holtorff, A. F. and Koch, F. C. (1940). J. biol. Chem., 135, 377.

Miller, S. and Mason, H. L. (1945). J. clin. Endocr., S, 220.

Medical Research Council Committee on Clinical Endocrinology (1951). Proposed Standard Method of 17-ketosteroid Determination. Lancet, 2, 585.

Poli, G. and Fantuzzi, B. (1945). Minerva pediat. (Torino), 6, 775

Talbot, N. B., Berman, R. A. and MacLachlan, E. A. (1942).' J. biol. Chem., 143, 211 .

Butler, A. M., Berman, R. A., Rodriguez, P. M. and MacLachlan, E. A. (1943). Amer. J. Dis. Child., 65, 364. 